\title{
Seasonal and stochastic effects in commodity forward curves
}

\author{
Svetlana Borovkova · Helyette Geman
}

Published online: 18 August 2007

(C) Springer Science+Business Media, LLC 2007

\begin{abstract}
In this paper we develop a new model for the dynamics of forward curves of commodities exhibiting seasonalities, such as natural gas, electricity or agricultural commodities. In the existing literature on the subject, the first state variable in multi-factor models is the commodity price, which combines seasonal and stochastic features and may be unobservable. We propose to use instead the average forward price, which is devoid of seasonality and conveys a more robust representation of the current forward curve level. The second factor in the model is a quantity analogous to the stochastic convenience yield, which accounts for the random changes in the forward curve shape. The well-known cost-of-carry relationship is significantly improved by introducing a deterministic seasonal premium within the convenience yield. We develop model estimation procedures and apply them to a number of energy markets.
\end{abstract}

Keywords Commodity futures $\cdot$ Forward curve $\cdot$ seasonality $\cdot$ Energy markets

\section{Introduction}

Commodity markets have recently experienced a dramatic growth, in terms of volumes and variety of traded contracts, number of operating exchanges and market

\footnotetext{
S. Borovkova $(\varangle)$

Department of Finance, Faculty of Economics, Free University of Amsterdam,

Amsterdam, The Netherlands

e-mail: sborovkova@feweb.vu.nl

H. Geman

Birkbeck, University of London, London, UK

H. Geman

ESSEC Business School, Cergy-Pontoise Cedex, France
} 
participants. The most important expansion has been in the trading of commodity derivatives, such as futures and options. Trading volumes in commodity futures have risen steadily over the past two decades on exchanges such as the InterContinental Exchange (ICE) and the New York Mercantile Exchange (NYMEX). Moreover, exchanges continually introduce futures and options on new commodities, such as electricity futures that are now trading in many countries after the liberalization of electricity markets. It is important to note at the start that forwards and futures commodity markets are the ones where most of the activity is taking place. In the case of oil for instance, volumes in these markets are nine times larger than those occuring in the spot market, and this ratio is consistently increasing with the arrival of new financial players.

Traditional pricing, hedging and volatility modelling techniques from equity and fixed income markets are not directly applicable to commodities, whose specific properties need to be taken into account. One such characteristic feature is seasonality. Seasonality in the spot prices of many agricultural and energy commodities-naturally arising from seasonal patterns in supply (e.g., harvest) and demand (e.g., cold weather)-is relatively well understood. It has been studied by a number of authors (see e.g., Milonas 1991) and can be successfully modelled by traditional time-series techniques. However, less attention has been given to seasonal effects in commodity forward curves. The shape of the forward curve reflects in all cases market fundamentals and anticipated price trends. Consequently, seasonal components of forward curves provide additional insight into how seasonality affects expected future spot prices. At the same time, however, seasonal features may bring noise to the analysis of the commodity price's evolution from an economic perspective.

For seasonal commodities, the shape of the forward curve is largely determined by the anticipation of seasonal demand and/or supply. In the case of energy commodities such as electricity and natural gas, prices are driven by seasonal demand: for instance, in the UK there is always a higher demand for gas and electricity during winter months, resulting in a price premium for futures expiring then. Typical forward curves for IPE ${ }^{1}$ electricity and natural gas futures, up to respectively 9 and 12 months to expiry, are shown on Fig. 1. These curves are observed on July 19, 2001, so the front-month contract is July. As expected, the peak in futures prices occurs for the contracts expiring in 6 months, i.e., in January 2002.

For agricultural commodities (e.g., soybean, wheat, coffee, cocoa), prices are driven by seasonal supply, hence they are generally higher before the harvest. Seasonal forward curves are not observed in the crude oil market, which is a world market.

Outside seasonality, a fundamental piece of information on commodity forward curves comes from the cash and carry relationship derived from the no-arbitrage assumption. Its early version (Brennan and Schwartz 1985) is the following:

$$
F(t, T)=S(t) e^{(r+c-\tilde{y})(T-t)},
$$

\footnotetext{
1 The London-based International Petroleum Exchange (IPE) has been absorbed by the ICE.
} 

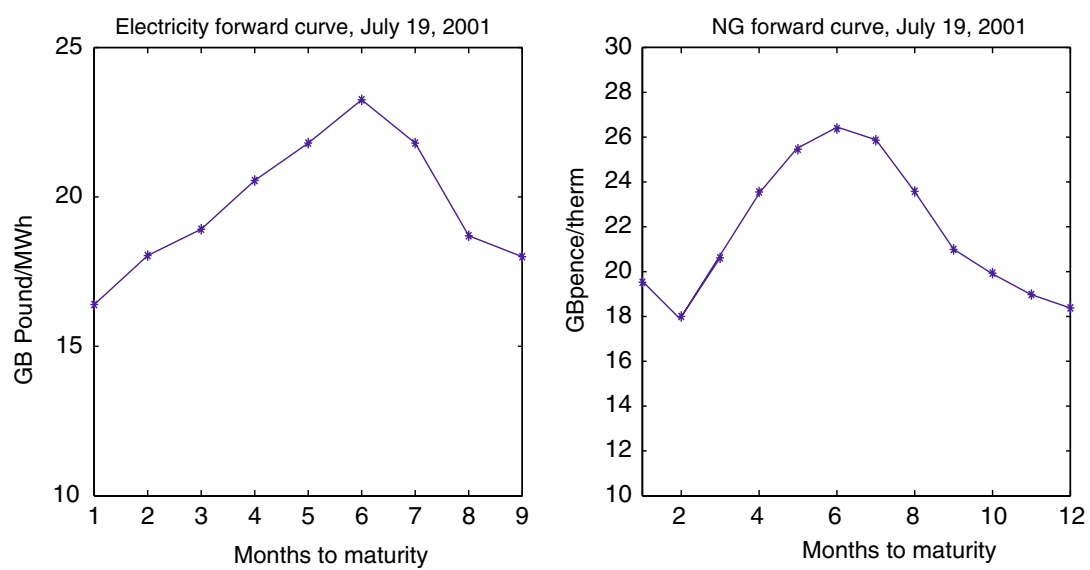

Fig. 1 UK electricity and natural gas forward curves on July 19, 2001

where $S(t)$ denotes the commodity spot price at date $t, F(t, T)$ the forward price ${ }^{2}$ for maturity $T ; r, c$ and $\tilde{y}$ respectively denote constant (continuously compounded) interest rate, cost of storage and convenience yield. As discussed by Kaldor (1939) and Working (1948), $\tilde{y}$ accounts for the benefit of owning the physical commodity rather than a futures contract written on it. The crucial value of this relationship is fully appreciated by the market participants. For instance, a trader who sold an option on the spot commodity will hedge his position in an opaque spot market through a liquid forward contract and its quantity will be defined by Eq. 1 .

Denoting $y=\tilde{y}-c$, the convenience yield net of storage cost, Eq. 1 implies that the forward curve at date $t$ is an increasing or decreasing function of the maturity $T$, depending on the sign of $(r-y)$, respectively called contango or backwardation. In a simple backwardated market, forward contracts with shorter maturities are more expensive than contracts expiring later. The contango market represents the opposite situation. These two types of forward curves are depicted in Fig. 2.

Whether the market is in backwardation or in contango depends on current price and inventory levels, transportation and storage costs, supply and demand equilibria, strategic and political reasons and possibly many other factors.

Allowing now interest rates and convenience yield to depend on time, the spotforward relationship becomes

$$
F(t, T)=S(t) e^{[r(t)-y(t)](T-t)} .
$$

Regarding the oil market, forward curves observed in the 1980s, 1990s and early 2000s were essentially backwardated, with a contango shape observed during crisis periods such as the Gulf war. For the first time, a hump-shaped curve has consistently prevailed since the beginning of the year 2006, with forward prices increasing up to

\footnotetext{
2 Throughout the paper, we assume non-stochastic interest rates. Hence $F(t, T)$ indifferently denotes the forward price and the futures price.
} 

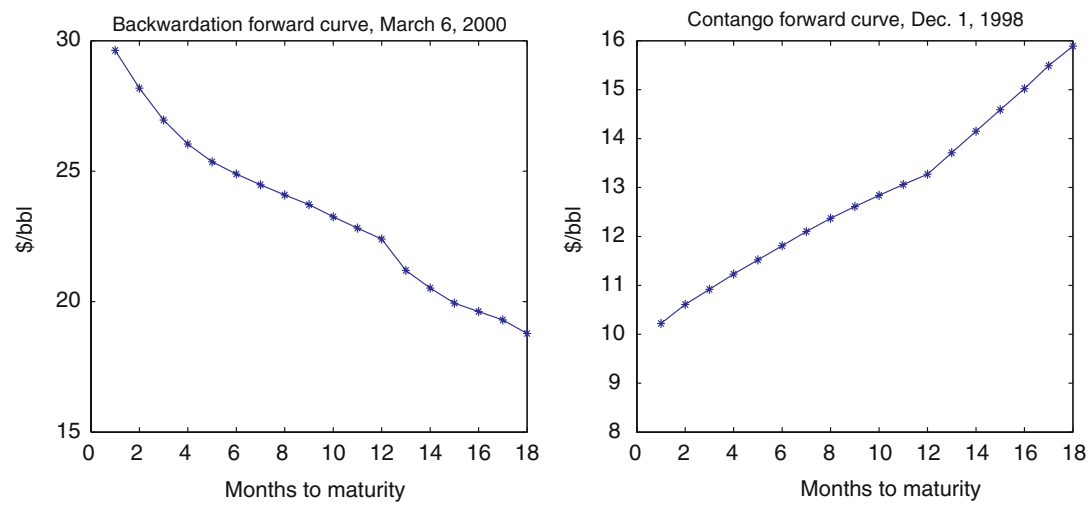

Fig. 2 Crude oil forward curves, backwardation and contango

12 or 13 months expiry and decreasing afterwards ${ }^{3}$ (see Geman 2007). We know from the theory of interest rate yield curves that a change in convexity along the forward curve does not contradict the no-arbitrage assumption. It is however inconsistent with a convenience yield independent of the maturity $T$, as stated in the classical form of the cost of carry relationship. The approach developed below would allow to capture this curvature change; our goal in this paper is to focus on seasonal commodities.

In the financial literature, the spot-forward relationship (2) is considered with various specifications of the convenience yield. In Brennan and Schwartz (1985), it is constant, while Black (1976) and Amin et al. (1994) consider the convenience yield $y(t)$ as a deterministic function of time. Gibson and Schwartz (1990), Schwartz (1997) and Litzenberger and Rabinowitz (1995) consider a more general situation, by defining $y(t)$ as a stochastic process.

The dependence of $y$ on time expresses the fact that the "reward" received by the holder of the physical commodity changes with the world inventories and, in turn, economic agents' preferences for the physical good rather than a paper contract. Our view in this paper agrees with this perspective but goes one step further, by considering $y=y(t, T)$ as a function of the forward contract's maturity $T$ as well as $t$. This is particularly indispensable in the case of seasonal commodities such as natural gas, sugar, corn: all of them presently in the spotlight because of the focus on energy and energy-related agricultural commodities.

Figure 3 shows a UK natural gas forward curve with maturities up to 68 months (i.e., more that 5 years ahead) and depicts the remarkable seasonality exhibited by the UK (and other regions) gas prices. This seasonality is essentially explained by demand, which is much higher in winter than in summer, and symmetrically observed by all market participants. Whether deterministic or not, this seasonality does not create arbitrage opportunities, namely positions built at zero initial cost and leading to positive or strictly positive liquidation values at maturity. In this respect the example

\footnotetext{
3 This phenomenon is generally explained by the massive arrival of hedge funds and other short term investors in the oil market; more distant maturities forward contracts remain only traded by the traditional players of the oil industry.
} 
Fig. 3 UK natural gas forward curve, March 7, 2007

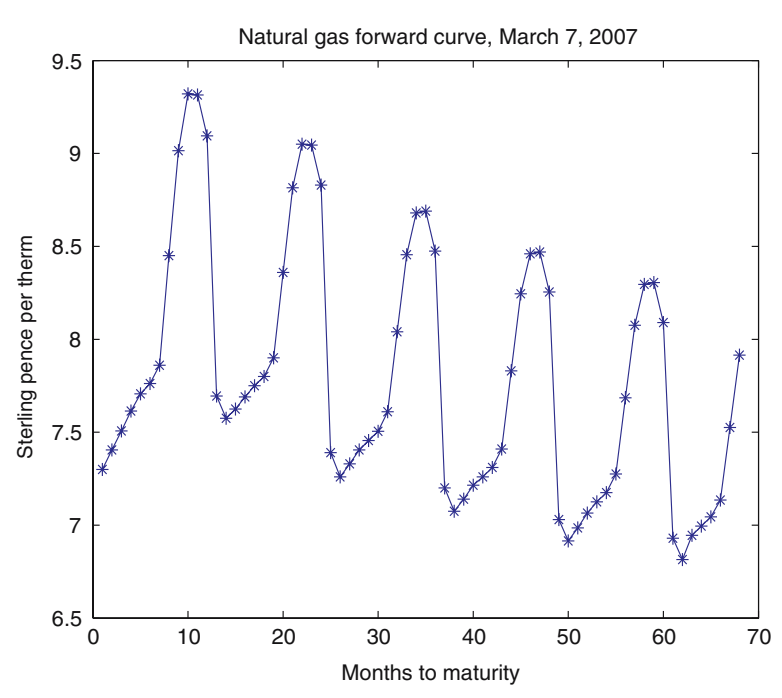

of the hedge fund Amaranth is quite instructive: this fund lost $\$ 6$ billion in summer 2006 , after gaining $\$ 1.5$ billion in summer 2005, through the same type of calendar spread positions in natural gas futures.

Returning to Eq. 2, the seasonality existing in the $T$ argument of the futures price $F(t, T)$ should be reflected in the cost of carry relationship. Since this $T$-seasonality cannot lie in the commodity spot price $S(t)$, it has to be embedded in the convenience yield $y$. Observe that this is in sharp contrast with the case of a stock making a continuous dividend payment at the rate $g(t)$ as in Merton (1973), where the spot-forward relationship is given by

$$
F(t, T)=S(t) e^{[r(t)-g(t)](T-t)}
$$

and the rate $g(t)$ may vary with time but does not exhibit any dependence on $T$.

As of now we shall denote the convenience yield (whether deterministic or stochastic) by $y(t, T)$ and rewrite Eq. 2 as

$$
F(t, T)=S(t) e^{[r(t)-y(t, T)](T-t)} .
$$

Note that this representation allows to emphasize the character of time-spread option carried by the convenience yield, as discussed for instance in Heinkel et al. (1990), or in Routledge et al. (2000).

To model the dynamics of the forward curve, one can follow the route familiar in yield curve stochastic modelling: choose one, two or three stochastic factors that drive the evolution of the forward curve and derive the futures prices from the assumed dynamics of these factors and no-arbitrage arguments. For instance in onefactor models, the single source of uncertainty is the commodity spot price (following e.g., a mean-reverting process), which also drives futures prices. In the more realistic two-factor models, proposed in the case of oil by Gibson and Schwartz (1990) and 
Litzenberger and Rabinowitz (1995), there are two sources of uncertainty: for instance, the spot price and the convenience yield, and futures prices are derived from these two factors by arbitrage arguments.

One problem with such models is that the derived forward curves are not consistent with the ones observed for seasonal commodities. To introduce seasonality into the model, Sorensen (2002) and Lucia and Schwartz (2002) use a two-factor model with the factors being a mean-reverting spot price with seasonal mean and a long-term equilibrium price. Geman and Nguyen (2005) extract a deterministic seasonal component in their three-factor model of the soybean forward curve. In all these models, seasonality is represented in the $t$ argument, but not in the delivery date $T$ of the futures price $F(t, T)$.

One step in our proposed direction was made by Amin et al. (1994). They consider the cost-of-carry model with seasonal (but deterministic) convenience yield and one stochastic factor, the spot price. Their model is related to the observation by Fama and French (1987) who find seasonalities in convenience yields, that can be explained by inventory fluctuations.

Futures prices of seasonal commodities are also driven by external stochastic factors other than the spot price: such as extreme weather circumstances (outside the average seasonal pattern), political crises within producing countries, market risk aversion and so forth. We choose to express these external influences by a stochastic convenience yield, while directly representing forward prices by a deterministic seasonal premium within the convenience yield. The case of non-seasonal but "segmented" oil forward curves can be treated by the same type of approach but is outside the scope of this paper.

The paper is organized as follows. In the next section we introduce the factors and the model. There we also discuss the dynamics of these factors and derive the corresponding futures prices and their volatilities. Section 3 addresses the problem of model estimation and Sect. 4 its application to energy markets. Section 5 concludes.

\section{Seasonal cost-of-carry model}

We construct a two-state variable model consistent with the points argued in the previous section. The first one is the average level of the forward curve, or the average forward price prevailing at date $t$, which we denote by $\bar{F}(t)$. We define $\bar{F}(t)$ as the geometric average of the current forward prices:

$$
\bar{F}(t)=\sqrt[N]{\prod_{T=1}^{N} F(t, T)},
$$

or, equivalently,

$$
\ln \bar{F}(t)=\frac{1}{N} \sum_{T=1}^{N} \ln F(t, T),
$$

where $N$ is the most distant liquid maturity. 
For seasonal commodities, we assume that $N$ is a multiple of 12 , i.e., we include maturities up to a whole year or an integer number of years. This assumption ensures that $\bar{F}(t)$ does not have any seasonal features. Other constructions of a non-seasonal $\bar{F}$ are possible. Furthermore, we are not limited to futures with regularly-spaced maturities, but can include all traded liquid maturities. To include all traded maturities, we could modify definition (6) by using a traded-volume-weighted average instead of the regular average.

Next, we define the seasonal premia $(s(M))_{M=1, \ldots, 12}$ as the collection of longterm-average premia (expressed in \%) on futures expiring in the calendar month $M(M=1, \ldots, 12)$ with respect to the average forward price $\bar{F}(t)$. We assume that the vector $(s(1), \ldots, s(12))$ is deterministic (its estimation from historical data will be described in Sect. 4). Furthermore, we shall require that $\sum_{M=1}^{12} s(M)=0$. This is a reasonable assumption, since $s(M)$ is defined with respect to the average price level. The seasonal premium could also be expressed as a trigonometric function of time with a period of 1 year; however, we find such a representation less appropriate, especially as futures expire monthly.

To relate the parameter $M$ (calendar month) to $T$ (the expiry date), the following rule is used: if $T$ is in a particular calendar month $M(M=1, \ldots, 12)$, then $s(T)=s(M)$. For instance, if a futures contract expires on February 25, 2008, then the seasonal premium for the contract always equals $s(2)$, regardless of the current date. Note that the same seasonal premium will be applicable to contracts expiring in February 2008 and 2009.

Now we introduce the seasonal cost-of-carry model. For any maturity $T$, we write

$$
F(t, T)=\bar{F}(t) e^{[s(T)-\gamma(t, T-t)(T-t)]},
$$

where $s(T)$ is the deterministic seasonal premium, and $\gamma(t, \tau), \tau=T-t$, defined by the relationship above, is called the stochastic convenience yield, or stochastic cost of carry net of seasonal premium, observed at date $t$ for time to maturity $\tau$.

Note that, in the seasonal cost-of-carry model (7) we have separated the dependence on maturity date $T$ from the dependence on time to maturity $\tau=T-t$. The maturity date (or, rather, maturity calendar month) influences the futures price via the seasonal premium $s(T)$, while the effect of time to maturity $\tau$ enters the futures price via the stochastic cost of carry aggregated up to time to maturity $\tau \gamma(t, \tau))$. The average forward price $\bar{F}(t)$ is only parameterized by the current date $t$. The choice of this first state variable is a key feature of our model.

Relationship (7) has a clear interpretation: futures expiring on date $T$ can either be at a premium or discount with respect to the current average forward price $\bar{F}(t)$, and this premium or discount is largely determined by the component $s(T)$, attached to the calendar month when the futures expire. For example, futures expiring in January will on average be at a premium (given by $s(1)$ ) with respect to $\bar{F}(t)$, independent of the current date $t$. This is why we define the seasonal premium as an absolute quantity and not as a rate: the premium for January futures is the same, whether today is March or September. In addition, the premium or discount of $F(t, T)$ with respect to $\bar{F}(t)$ also depends on factors other than the expiry month, and these stochastic factors (which also include "relative cost of financing") are summarized in $\gamma(t, \tau)$. The collection of 
stochastic convenience yields $\{\gamma(t, \tau)\}$ describes how the shape of the forward curve deviates from the typical seasonal pattern; it can be analyzed by principal component analysis techniques, introduced in Borovkova (2004) in the case of oil forward curves.

The quantity $\gamma$, defined by (7), is applicable to storable and non-storable commodities. Note that in the case of electricity, some authors (see e.g., Eydeland and Geman 1998) have argued that the notion of convenience yield does not really make sense since the absence of storability prevents any cash and carry argument, and in turn any spot-forward relationship between the spot price of electricity and forward prices. In the setting of this paper, the spot price plays no role and we are focusing on the random moves of the forward curve as a whole and at specific points. Hence, the stochastic cost of carry $\gamma$ as defined by Eq. 7 may be extended to the case of electricity.

The state variables in our model being the average forward price $\bar{F}(t)$ and the stochastic cost of carry $\gamma(t, \tau)$, we first consider two particular cases. If $\gamma(t, \tau) \equiv 0$, then our model is a one-factor model, driven only by the average forward price $\bar{F}(t)$; hence, the futures prices are completely determined by this quantity and the deterministic seasonal premium. If $s(T)=0$ for all $T$, then there is no deterministic seasonality in the futures prices and $\gamma(t, \tau)$ is reduced to the classical cost of carry and our model is similar to the Gibson and Schwartz (1990) two-factor model but with a spot price replaced by $\bar{F}(t)$.

In fact, by using $\bar{F}(t)$ as a new state variable, we circumvent many problems related to the spot price, while still having a factor indicative of the overall profile of the commodity market under investigation. It is known that spot prices are not readily available for many commodities. In such cases the futures price for the closest maturity is generally used as a proxy for the spot price. However, spot and futures markets are often quite dissimilar, and this approximation becomes questionable. As said before, the prime example of this situation is the electricity market, where spot prices can have huge spikes, while futures prices do not. In the Scandinavian electricity market Nordpool, the correlation between the spot and the nearby futures price ranged from 0.65 to -0.15 in the past few years, indicating that the futures price is a poor proxy for the spot price in the case of electricity, even in a market with a high ratio of hydroelectricity generation (see Geman 2005).

In all cases, the average forward price $\bar{F}(t)$ is more stable and reflects the overall price level better than the volatile spot price, and the argument applies to those commodity markets where the spot price is non-transparent because of the absence of a reliable index. There is finally an interesting theoretical relationship between the seasonal cost-of-carry model and the spot price. Let $S(t)$ denote the spot price. On the expiry day $t=T$ we have the following convergence relationship: ${ }^{4} F(t, t)=S(t)$. Hence, the model implies that

$$
S(t)=\bar{F}(t) e^{s(t)} .
$$

In those markets where there is no reliable proxy for the spot price, the model becomes highly useful as relationship (8) can be used to define such a proxy.

\footnotetext{
${ }^{4}$ However, in many markets (such as electricity) this convergence is not gradual but abrupt, i.e. discontinuous, and hence, does not hold in practice.
} 
An important advantage of introducing the quantity $\bar{F}(t)$ is that it is not seasonal (by construction), even if the spot price is. Hence, $\bar{F}(t)$ (or its logarithm) can be modelled as a positive mean-reverting process with a constant mean. The process $\gamma(t, \tau)$, on the other hand, may be viewed as fluctuating around zero, since all systematic deviations of futures prices from $\bar{F}$ are assumed to be due to season and hence, incorporated into $s(T)$. So $\gamma(t, \tau)$ can also be modelled as a mean-reverting process with mean zero.

Next, we are going to specify the stochastic dynamics of the state variables. Define $X(t)=\ln \bar{F}(t)$. We describe the dynamics of $X(t)$ and $\gamma$ under the real probability measure $P$ by the stochastic differential equations

$$
\begin{aligned}
d X(t) & =\alpha(m-X(t)) d t+\sigma d W_{1}(t) \\
d \gamma^{\tau}(t) & =-a^{\tau} \gamma^{\tau}(t) d t+\eta^{\tau} d W_{2}(t),
\end{aligned}
$$

where the volatility of $\ln \bar{F}(t)$ is assumed to be constant (but, brought together with volatilities of $\gamma^{\tau}$, still leads to a term structure of futures prices volatilities, as shown below). The convenience yields of all maturities $\gamma^{\tau}(t)$ are subject to a single source of uncertainty, given by the Brownian motion $W_{2}$, uncorrelated with the Brownian motion $W_{1}$ driving the average forward price. We view $\gamma^{\tau}$ as fluctuating around zero over time, since shocks to inventories get eventually absorbed by adjustment of the production, and $\ln \bar{F}$ reverts to a long-term value $m$, here supposed to be constant. The set $\left(\eta^{\tau}\right)_{\tau=1,2, \ldots, N}$ represents the stochastic convenience yield volatilities for different maturities.

We can substitute the stochastic differential Eqs. 9 and 10 into 7 and derive the dynamics of the futures $\log$-prices $Y(t, T)=\ln F(t, T)$ under the real probability measure:

$$
d(Y(t, T))=\left[\alpha(m-X(t))+\gamma^{\tau}(t)\left(a^{\tau} \tau+1\right)\right] d t+\sigma d W_{1}(t)-\eta^{\tau} \tau d W_{2}(t)
$$

So $Y(t, T)$ is obtained by integrating the above differential equation with the initial condition

$$
F(0, T)=\bar{F}(0) e^{s(T)-\gamma^{\tau}(0) T}
$$

Then $F(t, T)$ is log-normally distributed with variance

$$
\delta^{2}(t, \tau)=\sigma^{2}+\left(\eta^{\tau} \tau\right)^{2}, \quad \tau=T-t
$$

We can observe that, as in the case of the "extended" Vasicek model of interest rates (see Hull and White 1990), we obtain in our model a term structure of futures prices volatilities denoted by $\delta(t, \tau), \tau=1, \ldots, N$. Note that the dynamics and the volatility of the futures price only depend on the time to maturity $\tau$, and the dependence on the maturity date $T$ is reduced to the seasonal premium $s(T)$. 


\section{Model estimation and applications}

Suppose we have an historical dataset of $n$ daily forward curves with maturities up to one year: $(F(t, 1), F(t, 2), \ldots, F(t, 12))_{t=1, \ldots, n}$. The first unknown parameters of the seasonal cost-of-carry model are the collection of seasonal premia $(s(T))_{T=1, \ldots, 12}$. The statistical formulation of the model is the following.

We first note that the Eq. 7 can be written in logarithmic form as

$$
\ln F(t, T)=\ln \bar{F}(t)+s(T)+\tau \gamma(t, \tau), \quad \tau=T-t,
$$

or, if we denote $\Gamma(t, T)=\tau \gamma(t, \tau)$,

$$
Y(t, T)=X(t)+s(T)+\Gamma(t, T) .
$$

This is the so-called two-way fixed effects model, often used in the analysis of panel data (see e.g. Wooldridge 1999), or the two-way ANOVA ${ }^{5}$ model without replications, well-known in statistics. Such a model reflects the view that the current date and the maturity calendar month have different effects on the futures price, but the maturity calendar month essentially has a similar effect on futures prices of different dates $t$. In the statistical representation (15), $X(t)$ is the day effect, $s(T)$ is the (deterministic) maturity month effect, satisfying $\sum_{T=1}^{12} s(T)=0$, and $\Gamma(t, T)$ are mean-zero idiosyncratic errors. ${ }^{6}$ Note that the choice of $\bar{F}$ as the first state variable of our model does not induce a flat shape of the forward curve (never observed in the markets). Its value, however, immediately reflects where the market sees future spot prices. In the case of oil for instance, $\bar{F}$ went from values of the order of $\$ 20$ per barrel at the beginning of 2000 to levels of $\$ 60$ TO $\$ 70$ today.

The least squares estimator for the daily effect $X(t)$ is exactly the arithmetic average of $\log$-futures prices, i.e., $\ln \bar{F}(t)$. The least squares estimator for the maturity month effect $s(T)$ is the average deviation of the log-futures price from these daily averages:

$$
\hat{s}(T)=\frac{1}{n} \sum_{t=1}^{n}(Y(t, T)-X(t))=\frac{1}{n} \sum_{t=1}^{n}(\ln F(t, T)-\ln \bar{F}(t)),
$$

where $n$ denotes the number of days in the historical dataset. These estimates are unbiased and consistent since $\Gamma(t, T)$ is uncorrelated with $X(t)$ as we argued before, and with $s(T)$ (which is obvious, as $s(T)$ is non-random). Although the random variables $(\Gamma(t, T))_{t}$ are serially correlated, the estimators are still unbiased and consistent; for an overview of related asymptotic results, see Wooldridge (1999). In our case, the variance of the seasonal premium estimate $\hat{s}(T)$ involves autocorrelations of $(\Gamma(t, T))_{t}$, but can still be consistently estimated from the data. The model residuals

\footnotetext{
5 ANalysis Of Variance.

${ }^{6}$ For a given maturity, the quantity $\Gamma(t, T)$ contains the (log) differential cost of financing with respect to $\bar{F}$. The average of $\Gamma$ is indeed zero and each of them is arguably independent of the shocks driving $\bar{F}$, the "backbone" of the forward curve.
} 


$$
\hat{\Gamma}(t, T)=X(T)-Y(t, T)+\hat{s}(T)=\ln \frac{\bar{F}(t)}{F(t, T)}+\hat{s}(T)
$$

are the estimates of the daily aggregated convenience yields $((T-t) \gamma(t, T-t))_{t=1, \ldots, n}$, and the stochastic convenience yield itself can be obtained by

$$
\hat{\gamma}(t, T-t)=\frac{\hat{\Gamma}(t, T)}{T-t}
$$

for all available times to maturity $\tau=T-t=1, \ldots, N-t$ (expressed in months).

By definition, the daily average forward price $\bar{F}(t)$ is non-seasonal as long as we average futures prices up to a year or an integer number of years, e.g., 12, 24, or 36 months to maturity. If we have fewer than 12 expiries, then the unbiased estimates of $\bar{F}(t)$ (and hence $s(M)$ ) are not available. In this case we propose to use the estimation procedure described in the Appendix.

The nearby futures prices (i.e., those expiring in the current month) are often unstable, due to expiration effects and we chose to exclude them from the estimation procedure. If we have futures prices for expiries beyond 1 year ahead, we can estimate $\ln \bar{F}(t)$ by $\frac{1}{12} \sum_{T=2}^{13} \ln F(t, T)$. If fewer than 13 consecutive expiry months are available, then the Appendix procedure can be employed.

Next, the parameters of the mean-reversion dynamics (9) and (10) can be estimated from the observed series of $(\bar{F}(t))_{t=1}^{n}$ and $(\gamma(t, \tau))_{t=1}^{n}$, for all liquid times to maturity $\tau$. Since Eqs. 9 and 10 can be solved explicitly, we can apply for parameter estimation the exact maximum likelihood method.

In the next section we estimate the model parameters for oil, heating oil, natural gas and electricity futures prices. We use the estimated seasonal premium to deseasonalize the forward curves. This allows us to observe less prominent non-seasonal features of forward prices, normally obscured by the dominant seasonal effect.

\section{Application to energy futures}

We estimated the seasonal premia for natural gas, electricity, heating oil and crude oil futures. Our estimates are based on historical datasets of IPE futures prices, for natural gas (06.00-04.04), electricity (04.01-12.02), heating oil (01.00-04.04) and Brent crude oil (09.99-04.04). The seasonal premia for natural gas, electricity and heating oil are depicted in Fig. 4. The standard errors of the seasonal premia estimates are approximately 0.005 (half of a percent) for gasoil and natural gas and 0.003 (one-third of a percent) for electricity.

As expected, the estimated seasonal premium for crude oil is not significantly different from zero for all calendar months, and hence is not shown. For other energy commodities, futures expiring in winter are at a premium with respect to the average price level, and summer futures at a discount. This premium is the highest for natural gas futures: December gas futures are on average at a $28 \%( \pm 1 \%)$ premium. For electricity the December premium is also the highest, at $7 \%( \pm 1 \%)$. The seasonal premium for heating oil is generally smaller, and is at most $3 \%$. This reflects a wider 

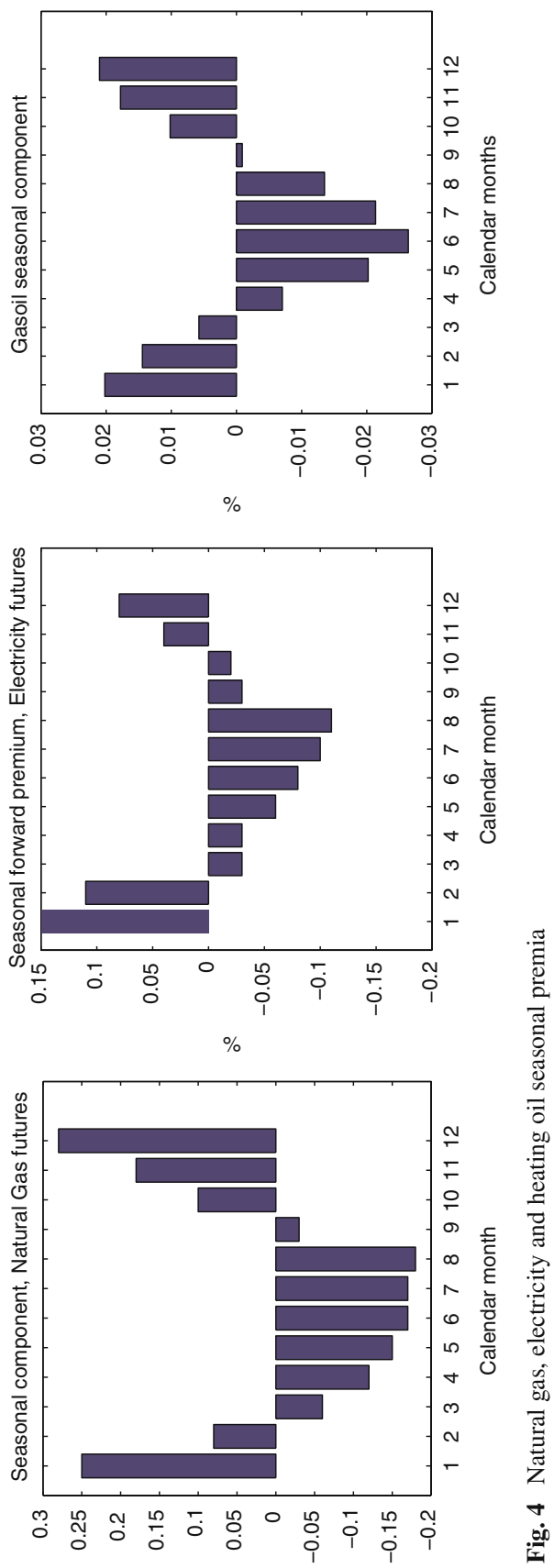
availability of storage for heating oil and a more mature market, similar to the crude oil market.

The residuals of model (17) are approximately normal for all commodities; Fig. 5 displays them for gasoil futures.

The model residuals provide us with the estimates for the stochastic convenience yield series, for all available times to maturity. Figure 6 shows the estimated convenience yields for natural gas and gasoil futures maturing in 2 months.

We estimated the parameters of the dynamics of $\gamma^{\tau}$, given in (10), for all available times to maturity $\tau$. Figure 7 shows the estimated term structure of the convenience yield volatilities $\left(\eta^{\tau}\right)$ for $\tau=1, \ldots, 12$, for natural gas and gasoil. Note that, for times to maturity longer than 3 months, the convenience yield volatility drops significantly. In our model, the futures price volatilities for a large part are determined by the convenience yield volatilities (see Eq. 13); we thus obtain consistency with the "Samuelson effect" of futures price volatility decreasing with maturity.

We also estimated the parameters of the mean-reverting process of $\bar{F}$, for four considered energy markets. Figure 8 shows the historical series of the logarithm of $\bar{F}(t)$ for the natural gas (June 2000-March 2004), gasoil (Jan. 2000-May 2004) and crude oil (Oct. 1999-May 2004) futures. All these series are devoid of seasonality, as expected from the definition of $\bar{F}$.

Table 1 summarizes the estimated mean-reversion parameters for the process $X(t)=$ $\ln (\bar{F}(t))$ specified in $(9)$, the standard errors are reported in parenthesis. The meanreversion rates and volatilities are classically expressed as annualized quantities.

Note that, for crude oil and gasoil, the mean-reversion rates and the volatilities of $\bar{F}(t)$ are comparable to those frequently reported in the literature for the corresponding spot prices. The mean-reversion rate of 2 (or the average reversion time of 6 months) is often reported for crude oil spot prices, while the volatility of $\bar{F}(t)$, at $28 \%$, is lower than the spot price historical volatility, which is in the range 30-40\% (Carmona and Ludkovski 2004 report a crude oil spot price volatility of $45 \%$ in the period $1994-$ 2002). However, for natural gas and electricity, the volatility of $\bar{F}(t)$ is much lower than historical volatilities of the spot prices, confirming that $\bar{F}(t)$ is indeed a stable quantity, which reflects the overall state of the futures market in a more robust way than the volatile spot price.

The estimated model can be used to generate realistic forward curves for seasonal commodities, for applications such as risk management of commodity portfolios, or any other application where a large amount of market scenarios-essentially forward curves in the case of commodities - is necessary. First, one can simulate sample paths of a daily average forward price $\bar{F}(t)$ and a vector of the stochastic convenience yields $\left(\gamma^{\tau}(t)\right)_{\tau}$ using Eqs. 9 and 10 with parameters estimated from historical data. Then, using these simulated daily values and the estimated seasonal premia $(\hat{s}(T))_{T=1, \ldots, 12}$, a forward curve can be generated using the seasonal cost-of-carry model (7) and the same procedure is repeated a number of times to generate a family of forward curves. These simulated forward curves will contain seasonal features as well as the stochastic behavior observed in historical forward curves. Moreover, the time evolution of daily generated forward curves will reflect the autoregressive structure observed in the market. 

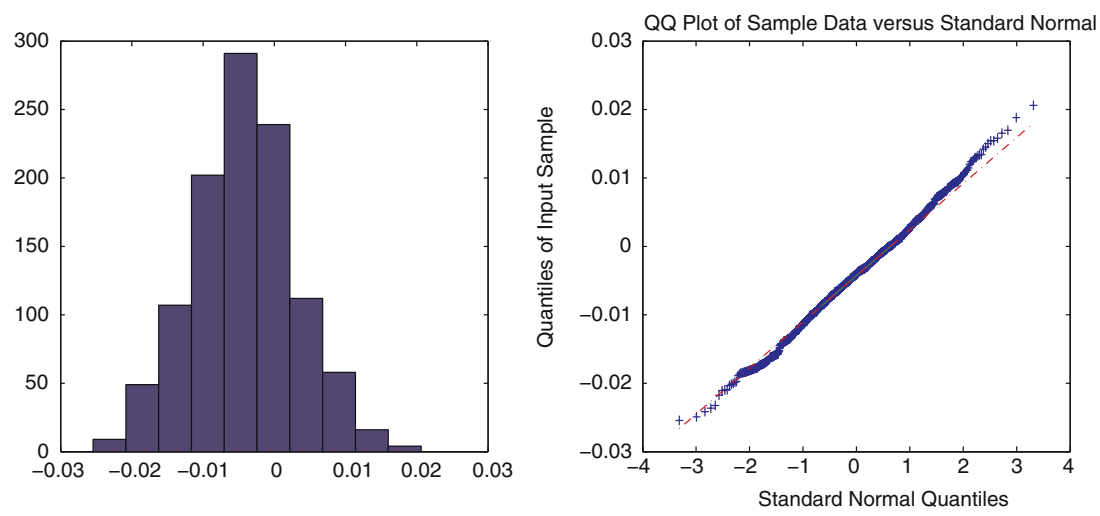

Fig. 5 Histogram and QQ-plot of the model residuals for gasoil futures
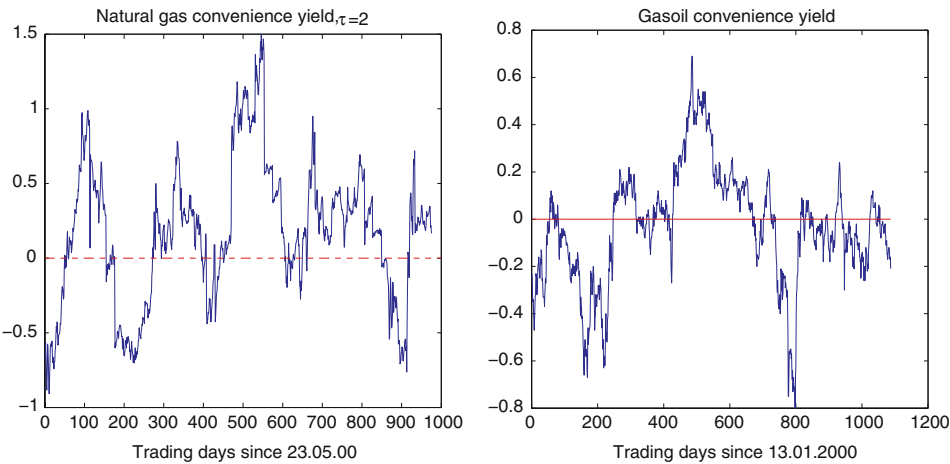

Fig. 6 Natural gas and gasoil stochastic convenience yields, $\tau=2$
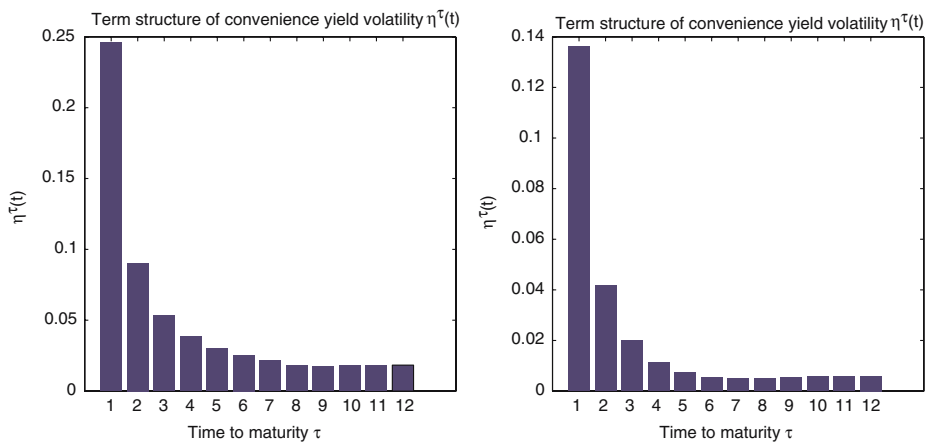

Fig. 7 Volatilities of natural gas and gasoil stochastic convenience yields 

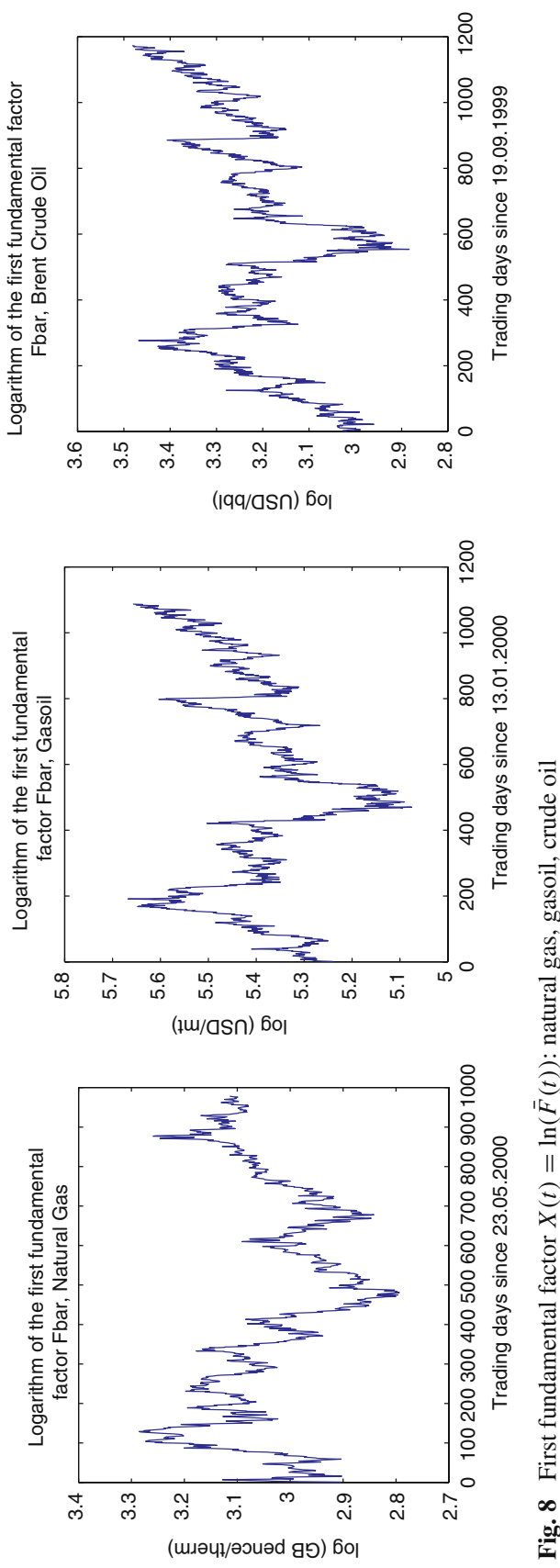
Table 1 Parameters of the mean-reverting process for $X(t)=\ln (\bar{F}(t))$

\begin{tabular}{lllll}
\hline & Electricity & Gas & Gasoil & Oil \\
\hline$m$ & $2.95(0.01)$ & $3.06(0.01)$ & $5.44(0.01)$ & $3.26(0.01)$ \\
$\alpha$ & $2.18(0.03)$ & $3.08(0.02)$ & $2.60(0.02)$ & $2.62(0.02)$ \\
$\sigma$ & $0.23(0.04)$ & $0.25(0.03)$ & $0.28(0.03)$ & $0.28(0.03)$ \\
\hline
\end{tabular}

Figure 9 shows three simulated forward curves up to 12 months to maturity, for gasoil, natural gas and electricity, all for June 1, 2007. Note that, for gasoil futures, the backwardation shape is slightly distorted by the anticipated seasonal premium; for natural gas and electricity, the seasonal component dominates.

The seasonal cost-of-carry model (and in particular, the estimated seasonal premia) can be also used to deseasonalize forward curves and reveal their stochastic features. Having estimated the seasonal forward premium $(\hat{s}(T))_{T=1, \ldots, 12}$, we can discount the futures prices by the corresponding $\hat{s}(T)$, to obtain the so-called deseasonalized forward curve

$$
\tilde{F}(t, T)=F(t, T) e^{-\hat{s}(T)}
$$

The left graph in Fig. 10 is the deseasonalized gasoil forward curve on October 6 , 2000. Now that all seasonal effects are removed, a clear backwardation pattern emerges, typical of the oil market around that date. The right graph is the deseasonalized forward curve of natural gas, plotted for the same date, October 6, 2000. Note that, after subtracting the seasonal premium it appears that the futures expiring in the next 3 months (November, December 2000 and January 2001) are less expensive than the average forward price $\bar{F}$, showing the importance of the stochastic factor $\gamma$.

Note that, according to the cost-of-carry model, the deseasonalized forward price can be expressed as

$$
\tilde{F}(t, T)=\bar{F}(t) e^{-\tau \gamma(t, \tau)}, \quad \tau=T-t,
$$

and its deviations from $\bar{F}(t)$ reflected in the stochastic convenience yield $\gamma(t, \tau)$. The higher (in absolute value) $\hat{\gamma}(t, \tau)$, the greater discrepancy between the observed $F(t, T)$ and "expected" futures price $\bar{F}(t) e^{s(T)}$. Figure 11 shows the estimates of the stochastic convenience yields for 2 and 6 months to maturity for natural gas futures prices in the period 2000-2003. The dotted lines indicate overall $95 \%$ confidence intervals around the zero mean.

Note that there are periods when $\hat{\gamma}(t, \tau)$ is outside the $95 \%$ confidence interval. During such periods, the corresponding futures prices are significantly higher or lower than the average seasonal premium would imply. On the basis of this information, a speculative trader may decide to sell highly priced futures contracts and buy them back when the market correction occurs. 

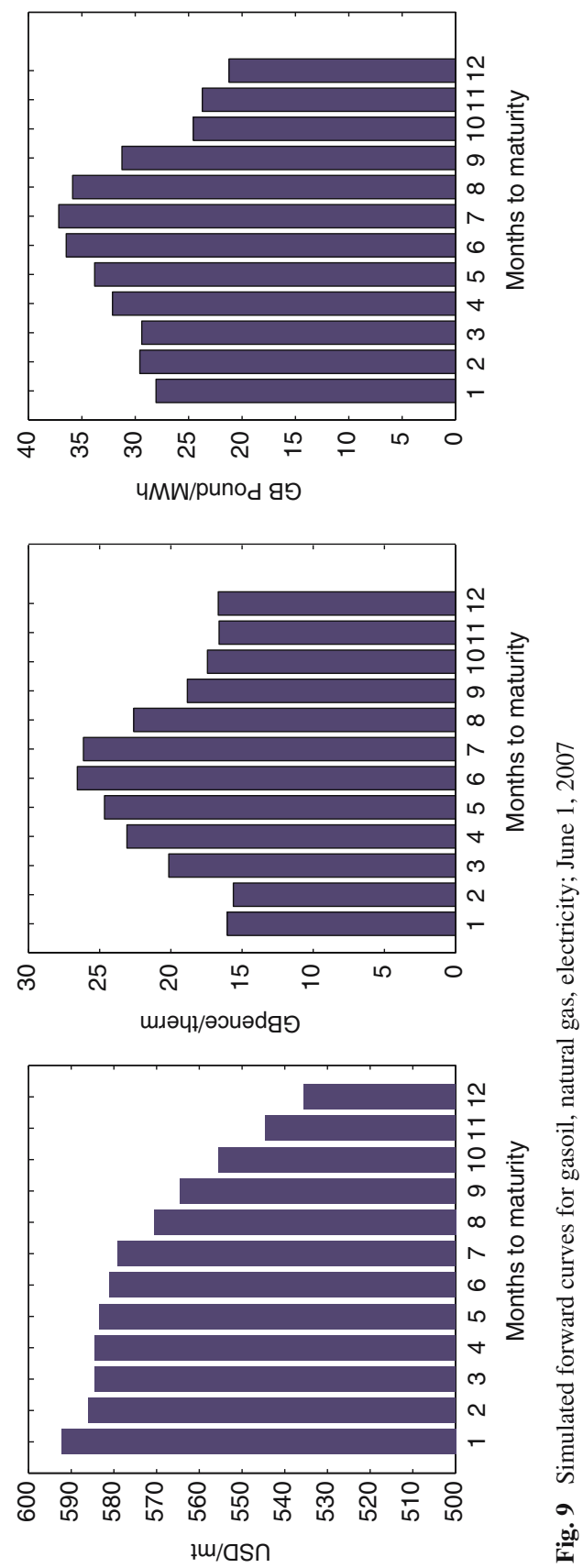

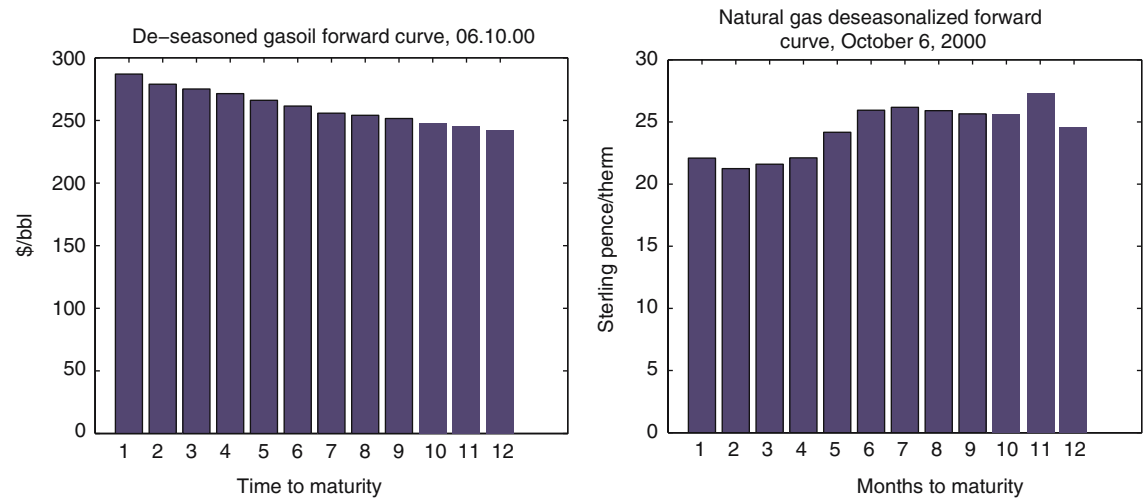

Fig. 10 Gasoil and natural gas deseasonalized forward curves on October 6, 2000
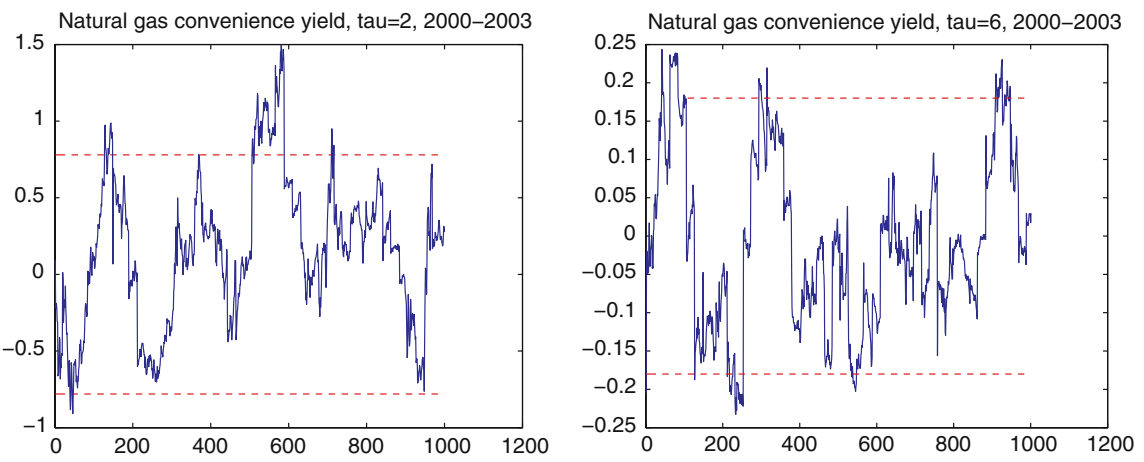

Fig. 11 Natural gas stochastic convenience yield, $\tau=2$ and 6; May 2000-March 2004

\section{Conclusions}

We introduced in this paper a new model for forward curves of seasonal commodities. The characteristic seasonal features of forward prices are captured by the seasonal forward premium, a meaningful quantity estimated from the historical data. The first fundamental factor in our model is the average forward price. It is a robust, non-seasonal quantity, which reflects the state of the forward market much better than a volatile and often unreliable spot price. The second factor is the stochastic forward premium. It allows us to extend the notion of convenience yield to non-storable commodities such as electricity, since it is defined with respect to the average forward price rather than the spot price. The model can be used to generate realistic seasonal commodities forward curves, for activities such as risk management of commodity portfolios and energy companies.

\section{Appendix}

This Appendix describes the procedure for estimating the seasonal premium and the daily average forward price if we have fewer than 12 maturities in our historical dataset. 
First, we obtain estimates of the differences $(s(M)-s(L))$ for all possible combinations of months $(M, L)$, by averaging $(\ln F(t, M)-\ln F(t, L))$ over the entire historical dataset. (Here we again use the fact that $\gamma^{\tau}(t)$ is zero on average for all $\tau$ ). In this way we obtain the matrix of difference estimates:

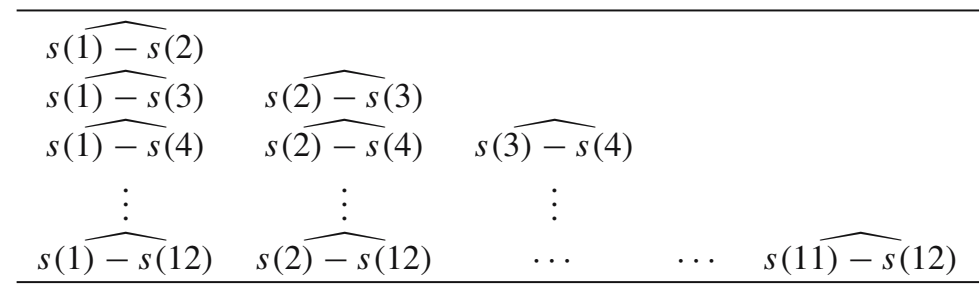

The individual estimates for $s(M)$ can be obtained by adding up the columns of the above matrix and using the restriction $\sum_{M=1}^{12} s(M)=0$. Denoting the sum of the first column by $\Sigma_{1}$, we observe that

$$
\Sigma_{1}=11 s(1)-\sum_{M=2}^{12} s(M)=12 s(1)
$$

So from the first column sum $\Sigma_{1}$ we obtain the estimate for $s(1)$ :

$$
\hat{s}(1)=\frac{\Sigma_{1}}{12}
$$

If $\Sigma_{2}$ denotes the sum of the second column, then we have

$$
\Sigma_{2}=10 s(2)-\sum_{M=3}^{12} s(M)=11 s(2)-s(1)
$$

and the estimate for $s(2)$ is then

$$
\hat{s}(2)=\frac{\Sigma_{2}+\hat{s}(1)}{11} .
$$

Continuing this procedure, we find the estimates for all $s(M), M=1,2, \ldots, 12$.

The unbiased estimates for $\bar{F}(t)$ can now be computed for all days in the historical database. If $N$ is the number of available expiries and suppose that at date $t$, the first expiry month is January. Note that in this case

$$
12 \ln \bar{F}(t)=\sum_{M=1}^{12} F(t, M) \approx \sum_{M=1}^{N} F(t, M)+(12-N) \ln \bar{F}(t)+\sum_{M=N+1}^{12} s(M),
$$


again, due to the fact that $\gamma^{\tau}(t)$ is essentially zero. Hence, the estimate of $\ln \bar{F}(t)$ is

$$
\widehat{\ln \bar{F}}(t)=\frac{\sum_{M=1}^{N} \ln F(t, M)+\sum_{M=N+1}^{12} \hat{s}(M)}{N} .
$$

If the first expiry month is not January, then in the numerator of the above expression we add to all available futures prices the estimated seasonal premia of the months that are missing from the historical dataset on the date $t$.

\section{References}

Amin, K., Ng, V., \& Pirrong, S. C. (1994). Valuing energy derivatives. In Managing energy price risk, Risk Publications.

Black, F. (1976). The pricing of commodity contracts. Journal of Financial Economics, 3(1/2), 167-179.

Borovkova, S. (2004). The forward curve dynamic and market transition forecasts. In D.W. Bunn (Ed.), Modelling prices in competitive electricity markets. John Wiley \& Sons, Ltd. p. 24.

Brennan, M. J., \& Schwartz, E. S. (1985). Evaluating natural resource investments. Journal of Business, 58 (2), $135-157$.

Carmona, R., \& Ludkovski, M. (2004). Spot convenience yield models for energy markets. In AMS mathematics of finance, G. Yin \& Y. Zhang (Eds.), Vol. 351 of Contemporary Mathematics, pp. 65-80.

Eydeland, A., \& Geman, H. (1998). Pricing power derivatives. RISK, September 1998, Risk Publications.

Fama, E. F., \& French, K. R. (1987). Commodity futures prices: Some evidence on forecast power, premiums and the theory of storage. Journal of Business, 60, 55-73.

Geman, H. (2005). Commodities and commodity derivatives. Wiley Finance.

Geman, H. (2007). Mean-reversion versus random walk in energy commodity prices. Advances in Mathematical Finance, Kluwer Publisher.

Geman, H., \& Nguyen, V. (2005). Soybean inventory and forward curve dynamics. Management Science, 51(7), 1076-1091.

Gibson, R., \& Schwartz, E. S. (1990). Stochastic convenience yield and the pricing of oil contingent claims. Journal of Finance, 45(3), 959-976.

Heinkel, R., Howe, M. E., \& Huges, J. S. (1990). Commodity convenience yields as an option profit. Journal of Futures Markets, 10(5), 519-533.

Hull, J. C., \& White, A. (1990). Pricing interest-rate derivative securities. The Review of Financial Studies, 3(4), 573-592.

Kaldor, N. (1939). Speculation and economic stability. Review of Economic Studies, 7, 1-27.

Litzenberger, R. H., \& Rabinowitz, N. (1995). Backwardation in oil futures markets: Theory and empirical evidence. Journal of Finance, 50(5), 1517-1545.

Lucia, J., \& Schwartz, E. S. (2002). Electricity prices and power derivatives: Evidence from the nordic power exchange, Review of Derivatives Research, 5(1), 5-50.

Merton, R. C. (1973). Theory of rational option pricing. Bell Journal of Economics and Management Science, 4(1), 141-183.

Milonas, N. T. (1991). Measuring seasonalities. In Commodity markets and the half-month effect. Journal of Futures Markets, 11(3), 331-346.

Routledge, B. R., Seppi, D. J., \& Spatt, C. S. (2000). Equilibrium forward curves for commodities. Journal of Finance, 55(3), 1297-1338.

Schwartz, E. S. (1997). The stochastic behaviour of commodity prices: Implications for valuation and hedging. Journal of Finance, 53(3), 923-973.

Sorensen, C. (2002). Modeling seasonality in agricultural commodity futures. Journal of Futures Markets, $22(5), 393-426$.

Wooldridge, J. M. (1999). Introductory econometrics: A modern approach. South-Western College Publishing.

Working, H. (1948). The theory of price of storage. Journal of Farm Economics, 30, 1-28. 